\title{
Environmetric study on air quality pattern for assessment in Northern region of Peninsular Malaysia
}

\begin{abstract}
Background and Objective: Causes of air quality problems detected are emission from vehicles, industrial emissions and open burning. The objective of this study was to determine the significant pollutant parameters contributing to air quality problems and also to look at air quality pattern at 12 air monitoring stations in the Northern region of Peninsular Malaysia (Perlis, Kedah, Pulau Pinang and Perak). Methodology: The data set was given from the Department of Environment, Malaysia (DOE) for the years 2002-2012 (11 years). Basically, air pollution index (API) parameters such as $\mathrm{O}_{3}, \mathrm{SO}_{2}, \mathrm{CO}, \mathrm{NO}_{2}$ and $\mathrm{PM}_{10}$ were involved in this study. Therefore, environmental metric techniques used such as cluster analysis (CA), perform three smaller groups compared 12 stations which has a same characteristic. This clusterization was also used to look air quality pattern based on yearly and specific monthly basis. It were shown that, 2005 and 2006 has a more stand out and different pattern. The third quarter of these years showed predominant and different pattern due to transboundary pollution. Discriminant analysis (DA) was used for differentiating each class. The study found that there were establish different variables, between each class. Principal component analysis (PCA), combined with factor analysis (FA), was used to know significant pollutant parameters based on five pollutants/gases in the air pollution index (API) which cause many activities either internal or external factors. Results: The study found that $\mathrm{SO}_{2}, \mathrm{NO}_{2}$ and $\mathrm{O}_{3}$ are the major pollutants contributing to degradation of air quality in the Northern region due to the combustion process from vehicles and industries. Conclusion: As a result of using the envirometric technique for analyzing huge data sets become better understanding air quality pattern and more clearly identify significant air pollutant parameters.
\end{abstract}

Keyword: Air pollutants; Pollution parameters; Environmetric techniques; Combustion process; Meteorological factors 